\title{
Reply to: Comment on Langlois et al.: Charnley-Kerboull total hip arthroplasty combining zirconia on polyethylene. A minimum eight-year follow-up prospective study
}

\author{
Jean Langlois • Moussa Hamadouche
}

Received: 1 May 2013 / Accepted: 1 May 2013 / Published online: 19 May 2013

(C) Springer-Verlag Berlin Heidelberg 2013

\section{Dear Dr. Pei,}

We appreciate that you read our paper with interest [1]. I would be more than happy to give you precise answers to your queries.

1. We regret to inform you, Dr. Pei, that this assertion is wrong. Indeed, as reported by Sychterz et al. [2], when analysing an initial radiograph too close to the time of surgery (2.9 weeks, range 1-15 weeks), there was a large difference between the centre of the head and that of the cup (mean, $1.1 \mathrm{~mm}$; range, 0.4-2.5 mm). This phenomenon could be related to postoperative oedema and/or intra-articular haematoma. That is why, as with most authors, we approximate the best baseline radiograph as that made at six weeks postoperatively.

2. Our publication was mainly a clinical survivorship stud$\mathrm{y}$, and not primarily based on a wear evaluation; radiological analysis of penetration was incidental, as it was based on a quite imprecise technique - the Livermore technique - which is defined by an accuracy of only $0.075 \mathrm{~mm}$. Moreover, as far as we know, the calculation of volumetric wear may have little benefit compared to two-dimensional penetration rates alone, as McCalden et al. already have published in an excellent review [3].

3. The paper from Cinotti et al. you mentioned is related to uncemented stems, which may sometimes be associated with thigh pain ( $8 \%$ of cases in that series) independent of any kind of loosening or material wear. This phenomenon, which could be related to adaptive bone remodelling, might sometimes lead to revision surgery of an uncemented stem [4]. Conversely, as far as we know, this has never been found in isolation from aseptic loosening and wear of polyethylene when using the cemented stems that were used in our study. Besides, as you know, pain was recorded in our study as a dimension included in the Merle d'Aubigné functional score.

\section{References}

1. Langlois J, El Hage S, Madi F et al (2013) Charnley-Kerboull total hip arthroplasty combining zirconia on polyethylene. A minimum eight-year follow-up prospective study. Int Orthop 37(3):355-360

2. Sychterz CJ, Engh CA Jr, Shah N, Engh CA Sr (1997) Radiographic evaluation of penetration by the femoral head into the polyethylene liner over time. J Bone Joint Surg Am 79(7):1040-1046

3. McCalden RW, Naudie DD, Yuan X, Bourne RB (2005) Radiographic methods for the assessment of polyethylene wear after total hip arthroplasty. J Bone Joint Surg Am 87(10):2323-2334

4. Brown TE, Larson B, Shen F, Moskal JT (2002) Thigh pain after cementless total hip arthroplasty: evaluation and management. J Am Acad Orthop Surg 10(6):385-392, Review
J. Langlois $(\bowtie) \cdot$ M. Hamadouche

Department of Reconstructive and Orthopaedic Surgery,

Université Paris Descartes, Hôpital Cochin (AP-HP), Paris, France

e-mail: jeangast@gmail.com 